\title{
A numerical methodology for predicting tool wear in Friction Stir Welding
}

\author{
A. F. Hasan ${ }^{\mathrm{a}, \mathrm{b}}$, C. J. Bennett*a ${ }^{\mathrm{a}}$, P. H. Shipway ${ }^{\mathrm{c}}$, S. Cater ${ }^{\mathrm{d}}$, J. Martin ${ }^{\mathrm{d}}$ \\ ${ }^{a}$ Gas Turbine and Transmissions Research Centre, Faculty of Engineering, University of \\ Nottingham, Nottingham NG7 2RD, United Kingdom \\ ${ }^{\mathrm{b}}$ Faculty of Engineering, University of Diyala, Iraq \\ ${ }^{c}$ Advanced Materials Research Group, Faculty of Engineering, University of Nottingham, \\ Nottingham NG7 2RD, United Kingdom \\ ${ }^{\mathrm{d}}$ TWI Technology Centre - Yorkshire, Wallis Way, Catcliffe, Rotherham, S60 5TZ, \\ United Kingdom \\ *email: chris.bennett@,nottingham.ac.uk
}

\begin{abstract}
A novel methodology for predicting tool wear in FSW based on a CFD model, coupled with a modified Archard equation, is presented considering the effect of the deformation of the highly viscous flow around the tool on tool wear. A validation process is proposed to ensure robust results when using this methodology. A study was carried out to predict the wear on a dome shaped FSW tool, indicating that high wear was predicted at the shoulder edge due to rapidly changing flow, and that the interaction of the axial flow with the pin causes a bifurcation of the flow and an associated increase in pressure at the mid axial position of the pin, again leading to high wear in this location. The proposed approach could be used as a
\end{abstract}


method for calculating tool wear and determining the effective limits of tool use, without the need for experimental trials.

Keywords: Friction Stir Welding; Computational Fluid Dynamics; Tool Wear; Modelling

\section{NOMENCLATURE}

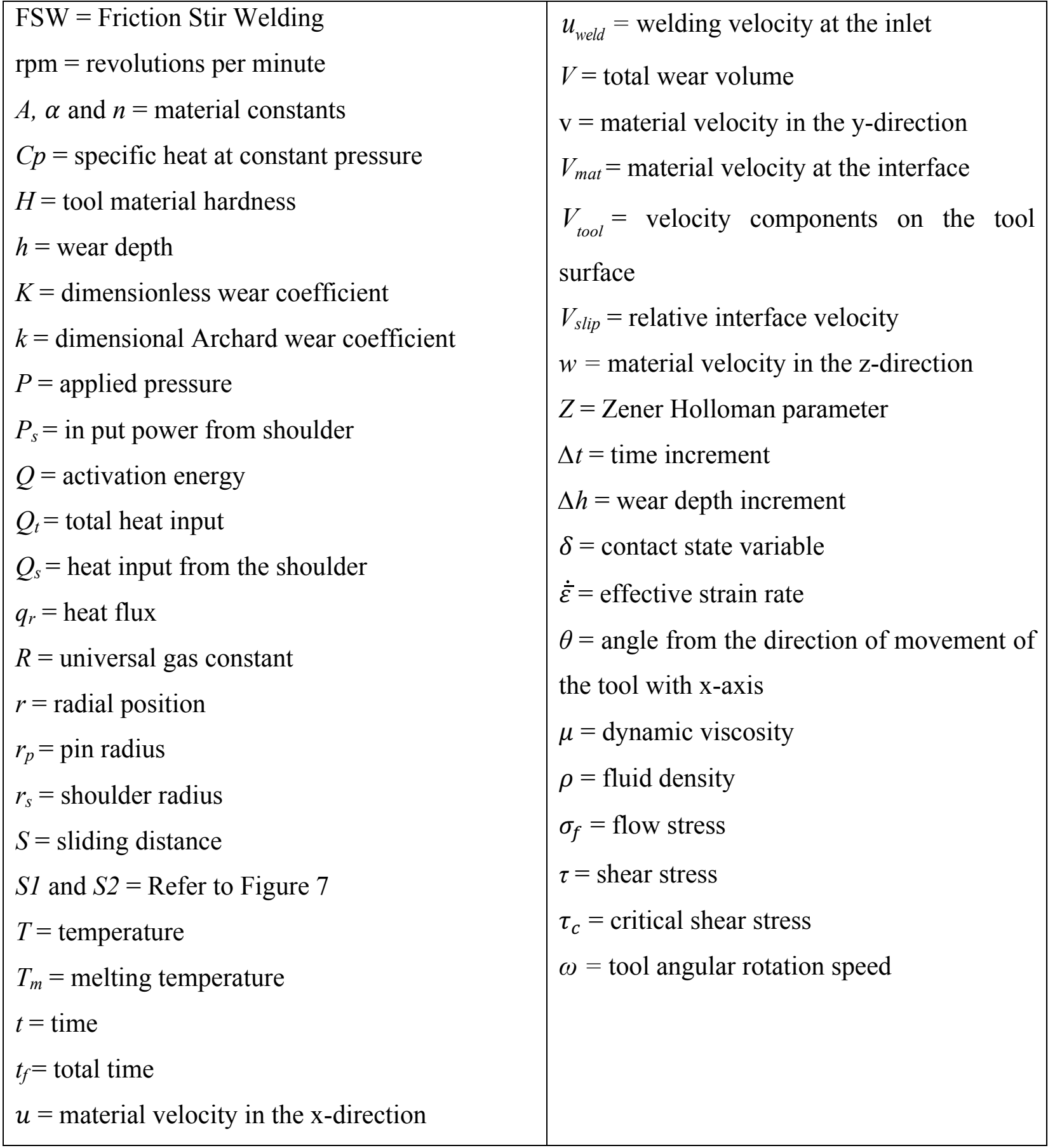




\section{Introduction}

Friction stir welding (FSW) is a solid-state joining process that has many advantages including the ability to join high strength aluminium alloys, as well as dissimilar metals that are hard to join by conventional fusion techniques (Sinha et al., 2008, Sued et al., 2014). As the heat input in the process produces temperatures below the melting point, additional advantages exist such as low distortion, wide chemical tolerance and high mechanical strength due to grain refinement in the thermo-mechanically affected zone (TMAZ) (McPherson et al., 2013). Although it has been shown that the FSW process has the ability to produce joints in various types of metals, tool integrity issues seem to be one of the main barriers to wider application of this technique at present, particularly when joining metal matrix composites (MMCs) and steel with a thickness of $6 \mathrm{~mm}$ and above (Ishikawa et al., 2009).

Advances in tool materials have allowed the process to be used for increasingly demanding applications, however, the degradation of FSW tools in the form of wear (Gibson et al., 2014), has remained an issue, highlighted by Wang et al. (2014), who reported that tool wear in FSW leads to a decreasing in the stirring action and a lack of the vertical movement of the weld material through the plate thickness.

Wear can be defined as the removal of material from a surface due to relative motion, such as sliding of surfaces in contact. In complex industrial contexts, both the rate and spatial distribution of wear in a contact can be affected by the geometrical changes associated with any wear that has occurred up to that point in time. Moreover, the materials properties themselves may be dependent upon the preceding history of the contact (for example, due to frictional heating). In such complex and interdependent systems, simulation can provide important information regarding these quantities required for the investigation of wear 
phenomena and tool wear. A number of workers have used finite-element analysis to develop time-marching models of wear, where wear at any instant is dependent upon changes that have taken place in previous steps. Ersoy-Nürnberg et al. (2008) predicted the tool wear in the sheet metal forming process numerically, showing that the progression of wear can be predicted at any stage of the tool life using their simulation strategy. Akkök et al. (2013), who developed a methodology to predict the life of a rocket launcher release latch, concluded that time dependent variables, such as contact pressure and sliding distance, should be considered during wear calculations. The approaches presented in these works show that numerical simulation can be a powerful tool to investigate wear phenomena. However, until now, experimental work has remained the primary method of investigating tool wear in FSW.

According to Prado et al. (2003), who studied the tool wear in the FSW of an aluminium matrix composite when using a threaded tool geometry at high rotation speed, the main cause of tool material loss during the FSW process is abrasive wear, while Thompson (2010) stated that the removal of material through excessive shear deformation is another reason for the degradation of FSW tools, when he assessed the wear rate when welding steel. A study by Poelman (2011) when investigating the wear rate in the FSW of steel concluded that plastic deformation can also cause tool mushrooming during the initial stage of welding. Tool mushrooming is when the tool height is decreased and the tool radius is expanded (Michael, 2012). Both of these effects can lead to what is termed "self-optimization" of the pin geometry during the process for some material combinations (Prado et al., 2003). Selfoptimization can be defined as the situation when, after a preliminary wear period, the tool shape is worn to a shape which results in low rates of further wear.

The most common experimental method used for the assessment of tool wear in the FSW process is the photographic technique, where the change in tool volume is assessed using image-processing to compare an image of the unworn tool with an image of the tool after a 
specific length of welding. Using this technique, Prado et al. (2003) concluded that the rate of tool wear increased with increasing tool rotation speed. Weld traverse speed is also an important factor that contributes to wear and self-optimization of the tool geometry as highlighted by Shindo et al. (2002), who discovered that wear of the pin features (threads) increased significantly when the weld traverse speed was increased. Michael (2012) used digital profilometry, in the form of a laser scanner that provided a $2 \mathrm{D}$ tool profile, to assess the wear rate of the tool when welding of steel and observed that the wear in the tool taper portion was much greater than pin tip and shoulder zone. The wear and deformation of an FSW tool used to weld AISI 304 austenitic stainless steel when using different shoulder diameters and combinations of rotation and welding speeds was assessed by Siddiquee and Pandey (2014) using the 3D white light scanning technique. They observed the highest wear volume when using the highest weld traverse speed and the lowest tool rotation speed, while the largest single factor affecting tool wear was the shoulder diameter. These researchers successfully assessed tool wear in the FSW process and the results gained from these efforts have been directed towards providing a better understanding of the wear mechanisms, such as the self-optimization phenomena (Prado et al., 2003), abrasion wear and intergranular wear (Michael, 2012), diffusion wear and adhesion wear. (Siddiquee and Pandey, 2014). However, the complexities of the FSW system do not readily allow the roles of the individual process parameters to be understood in terms of the rate of wear of the tool.

A study by Gan et al. (2007) considered the FSW of L80 steel plate using a cylindrical commercially pure tungsten $(\mathrm{CPW})$ tool. They developed a 2D axisymmetric model using the ABAQUS FEA software to predict the tool deformation during the process and the results were compared with experimental data. The model successfully predicted the plastic deformation in terms of tool shortening, but did not consider radial changes in geometry resulting from wear. The study concluded that plastic deformation and wear were the main 
causes of CPW FSW tool degradation and that the mechanical properties of the tool material at high temperatures are important factors that affect tool mushrooming. Mandal et al. (2008) suggested that further efforts are needed to reduce the tool wear in FSW by investigating the thermochemical conditions during the welding process, while Prater and Strauss (2010) suggested that future work should be undertaken to produce a model of FSW tool wear that could include dimensionless parameters which linked rotation speed, traverse speed and welding distance. The work of Buffa et al. (2012) also recommended producing a numerical wear model including abrasive and adhesive wear. Therefore, it would be advantageous to produce a numerical model that is able to predict the tool deformation and tool wear during the FSW process that would allow the evolution of wear to be better understood.

It is well established that FSW is an extreme plastic deformation process, where the flow regime is characterized by solid-state material flow. Examining and characterizing the flow behaviour in the FSW process assists in the understanding of tool wear in this process. The review study by Murr (2010) documented that the complex flow regime generated during the FSW process has an effect on the pressure distribution on the tool surface at different process parameters, which need to be optimized to produce a sound weld. Tool degradation generates different flow behaviour during welding, which could affect the resultant microstructure of the weld (Prado et al., 2003). Computational fluid dynamics (CFD) is a technique that can provide valuable insight into the flow behaviour during the FSW process; it was first used to address this problem by Colegrove (2004), who investigated the flow behaviour for different FSW tool designs and predicted the temperature distribution, tool forces and the pressure distribution. He stated that CFD is an appropriate tool for modelling the FSW process due to the capability to deal with different flow regimes and include the effects of heat flow through using coupled thermal/flow analyses. Recently, CFD was used to highlight the difference in 
the velocity profile, strain rate and mechanically affected zone when using unworn and worn tool geometries by Hasan et al. (2015).

It is well known that degradation of the tool is very common during the FSW process. However, only the study by Gan et al. (2007) has sought to predict tool degradation in FSW, and this study only considered degradation due to deformation rather than attritive wear. In light of this, a methodology for calculating tool wear in FSW based upon a CFD model is presented in this study by predicting the effect of the deformation of the highly viscous flow around the tool on tool wear. A modified Archard equation, implemented in MATLAB, was used to calculate the wear depth on a dome shaped FSW tool. This modelling approach could be used to investigate the effects of process parameters on tool wear and as a method for calculating tool wear without the need for experimental trials.

\section{Experimental tests}

A series of welds was carried out on the Transformation Technologies Inc. (now MTI) FSW machine RM2 (FW32) at TWI Yorkshire, which has a force capability of $100 \mathrm{kN}$ in the vertical $(\mathrm{Z})$ axis and $45 \mathrm{kN}$ in both $\mathrm{X}$ and $\mathrm{Y}$ horizontal axes, a torque capability of $225 \mathrm{~N} \mathrm{~m}$, and a geared maximum rotation speed of $2000 \mathrm{rpm}$. The machine has a high concentricity spindle, which enables ceramic and refractory metal FSW tools to be evaluated.

The tools used were of tungsten - rhenium - hafnium carbide (WRe-HfC) material with a simple domed profile as shown in Figure 1. The tool was measured before and after use using a Mitutoyo shadowgraph and the degree of wear on the tool recorded.

Argon gas shielding was used for all the welds to prevent oxidation of both the tool and the weld. The workpiece material was a $6 \mathrm{~mm}$ thick plate of AISI 304 austenitic stainless steel which was degreased with acetone prior to welding and clamped to the machine bed using 
standard finger clamps. The tools were plunged directly into the steel plate with no pilot being drilled first to aid entry into the steel.
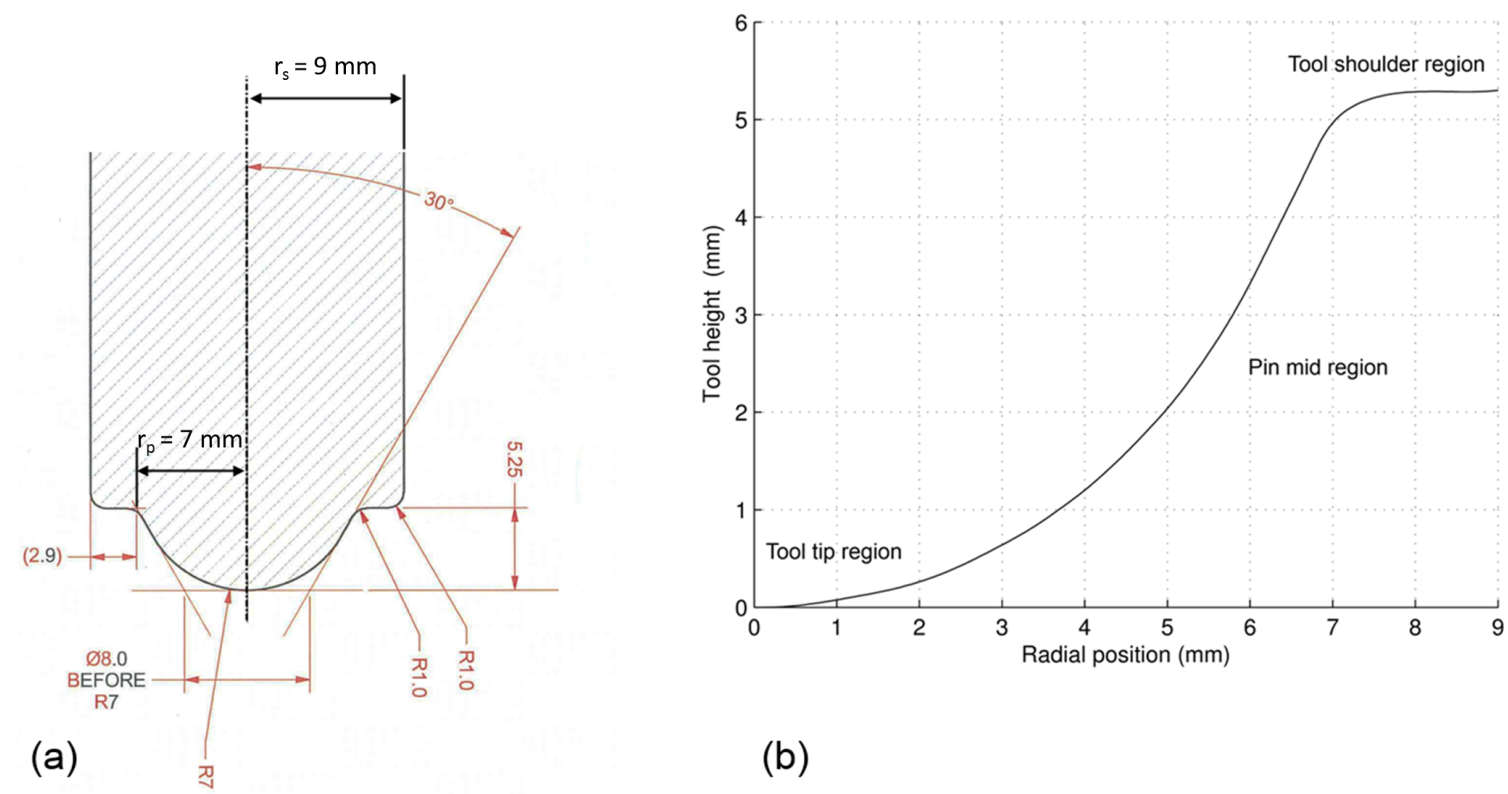

(b)

Figure 1 Tool geometry used in the study; (a) tool dimensions, (b) tool regions.

The welds were made at a tool traverse speed of $2.5 \mathrm{~mm} \mathrm{~s}^{-1}$ and rotation rate of $225 \mathrm{rpm}$. A total of three welding distances were considered both experimentally and numerically, as shown in Table 1, to validate the developed approach.

Table 1 Process parameters

\begin{tabular}{|c|c|c|}
\hline $\begin{array}{c}\text { Weld Traverse speed } \\
{\left[\mathbf{m m ~ s}^{-1}\right]}\end{array}$ & $\begin{array}{c}\text { Tool Rotation speed } \\
{[\mathbf{r p m}]}\end{array}$ & Weld distance [mm] \\
\hline 2.5 & 225 & 2,4 and $6 \times 10^{3}$ \\
\hline
\end{tabular}




\section{$3 \quad$ CFD modelling}

\subsection{Model description}

In this study, a steady state, 3D coupled thermal-flow model of the friction stir welding (FSW) process was generated using the commercial CFD software FLUENT. This model was used to extract the pressure and velocity values in order to predict the tool wear that occurs during the FSW process. Full details of this model can be found elsewhere (Hasan et al., 2015). The geometry of the computational domain of the model was a rectangular cuboid with the dimensions presented in Table 2; the tool was a dome shape, as shown in Figure 1, while the detail of the computational domain and the boundary conditions is presented in Figure 2.

Table 2: Model Dimensions

\begin{tabular}{|c|c|}
\hline Dimension & $\begin{array}{c}\text { Value } \\
{[\mathbf{m m}]}\end{array}$ \\
\hline Plate length & 304 \\
\hline Plate width & 203.2 \\
\hline Plate thickness & 6 \\
\hline Weld distance & 2,4 and $6 \times 10^{3}$ \\
\hline
\end{tabular}

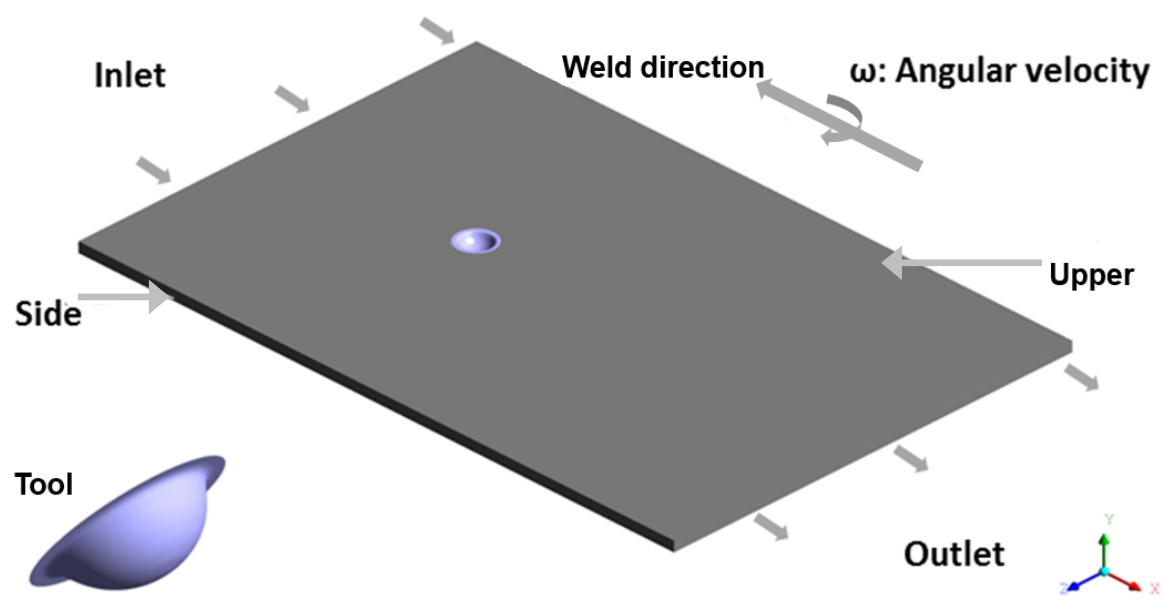


The dynamic viscosity of the material was defined as a function of temperature and strain rate through the use of a User Defined Function (UDF). In the UDF, the flow stress and ZenerHollomon parameter are calculated as defined in equations 1 and 2 respectively and then the dynamic viscosity is calculated using equation 3 . The material constants and further relevant properties for 304 stainless steel are shown in Table 3.

$\sigma_{f}=\frac{1}{\alpha} \sinh ^{-1}\left[\left(\frac{Z}{A}\right)^{\frac{1}{n}}\right]$

where:

$Z=\dot{\bar{\varepsilon}} \exp \left(\frac{Q}{R T}\right)$

$\mu=\frac{\sigma_{f}}{3 \dot{\bar{\varepsilon}}}$

3

Table 3 Material properties (Tello et al., 2010, Nkhoma and Kasanalowe, 2014, Selvaraj, 2013).

\begin{tabular}{|c|c|}
\hline Material property & $\begin{array}{c}\text { Value (304 stainless } \\
\text { steel) }\end{array}$ \\
\hline$\rho$, density & $7406 \mathrm{~kg} \mathrm{~m}^{-3}$ \\
\hline$A$, material constant & $1.62 \times 10^{16} \mathrm{~s}^{-1}$ \\
\hline$\alpha$, material constant & $0.008 \times 10^{6} \mathrm{~Pa}^{-1}$ \\
\hline$n$, material constant & 6.1 \\
\hline$Q$, activation energy & $446 \mathrm{~kJ} \mathrm{~mol}^{-1}$ \\
\hline$R$, gas constant & $8.314 \mathrm{~J} \mathrm{~K}^{-1} \mathrm{~mol}^{-1}$ \\
\hline$C_{P}$, specific heat at $1273 \mathrm{~K}$ & $610 \mathrm{~J} \mathrm{Kg} \mathrm{k}^{-1}$ \\
\hline$\lambda$, thermal conductivity at & $30 \mathrm{~W} \mathrm{~m}^{-1} \mathrm{~K}^{-1}$ \\
\hline
\end{tabular}


A slip-stick condition was implemented on the tool surface by defining the material interface velocity, $V_{\text {mat }}$, as the boundary condition on the tool surface which is related to the tool velocity, $V_{\text {tool }}$, by the contact state variable, $\delta$, defined by equation 4 . The position-dependent tool velocity $V_{\text {tool }}$ is defined as the velocity on the surface of the tool given by $r \omega$.

$\delta=\frac{V_{\text {mat }}}{V_{\text {tool }}}$

Therefore, $V_{\text {mat }}$ is defined as the velocity components for $u$ and $w$ which are shown in equations 5 and 6 , while $v=0$.

$u=(1-\delta)\left(\omega r \sin \theta-u_{w e l d}\right)$

$w=(1-\delta)(\omega r \cos \theta)$

In this work, a constant value of 0.07 was used for $\delta$; this assumption was made based on the work of Chen et al. (2008), where they determined the value of $\delta$ experimentally based on the estimation of the pin travel distance after one revolution and the location of the flow front of each of the deformed layers around the pin. This value is included as wear is caused by relative motion between surfaces; therefore, in order to predict tool wear in this case, a relative interface velocity is required, $V_{\text {slip }}$, which can be calculated according to equation 7 .

$V_{\text {slip }}=V_{\text {tool }}-V_{\text {mat }}$ 


\subsection{Thermal model}

It is known that the properties of 304 stainless steel are very sensitive to temperature and strain rate (Belyakov et al., 1998), and that the variation of temperature through the plate thickness has a significant effect on the pressure and velocity in the weld zone (Liechty, 2008). It is therefore important to consider thermal effects and include heat input in the FSW model for this application. The tool in the FSW process generates heat through friction and plastic deformation. The study of Chao et al. (2003) revealed that frictional heat is the main source of the heat input into welding plate and that approximately $95 \%$ of the total heat input is distributed to the plate and about $5 \%$ is input to the tool surface. Initially during the process, contact occurs between the rotating tool and the workpiece, frictional heat is generated and is conducted into the body of the workpiece. After that, localized heating caused by the shoulder causes the workpiece to deform plastically under these conditions (Selvaraj, 2013).

Hamilton et al. (2008) proposed that the power required for the tool to cause shear deformation of material in the FSW process is given by equation 8 .

$P_{s}=\frac{2 \pi}{3} \tau \omega\left(r_{s}^{3}-r_{p}^{3}\right)$

where $r_{s}$ is the maximum shoulder radius, $r_{p}$ is the pin radius, $\omega$ is tool rotation speed and $\tau$ is the material shear stress, which can be determined from the dynamic viscosity and effective strain rate using equation 9 (Nandan et al., 2007).

$\tau=3 \dot{\bar{\varepsilon}} \mu$ 
A steady-state thermal model was implemented and the temperature in the domain was calculated. Moreover, it was assumed that all of the power input (equation 8) in the FSW process is converted to heat; therefore, the total heat input $Q_{t}$, was equal to the power input in the process (Selvaraj, 2013) $\left(Q_{t}=P_{s}\right)$. The majority of the heat is generated by the shoulder of the tool, with the contribution of the pin being less than $15 \%$ of the total heat input (Schmidt et al., 2004). It was therefore assumed in this work that the heat input came from the shoulder only, so in this case $Q_{s}=Q_{t}=P_{s}$, where $Q_{s}$ is the heat input from the shoulder.

The value of the shear stress is directly proportional to the value of the strain rate and material viscosity; Nandan et al. (2006) documented that no significant plastic deformation occurs below a viscosity of $4 \times 10^{6} \mathrm{~Pa}$ s for 304 stainless steel. This value of viscosity was used by Selvaraj (2013) to determine the critical value of shear stress $\left(\tau_{c}\right)$ using equation 9 leading to a value of $15 \times 10^{6} \mathrm{~Pa}$, and a corresponding temperature of $1038^{\circ} \mathrm{C}$, approximately 0.7 of the melting temperature $\left(T_{m}\right)$. Therefore, it can be argued that when the temperature in the FSW process is less than $0.7 T_{m}$, the flow stress of the material is high enough for the plastic deformation to be insignificant. However, when the temperature is greater than $0.7 T_{m}$, the flow stress decreases, leading to plastic deformation.

Zhu and Chao (2004) experimentally determined the value of $Q_{t}$ from the measured torque during FSW of 304 stainless steel to be in the range 1760 to $2240 \mathrm{~W}$. This range has been further confirmed numerically by Zhu and Chao (2004) and Selvaraj (2013). In the current study, equation 8 was used to calculate $Q_{s}$ based on the value of $\tau=15 \times 10^{6} \mathrm{~Pa}$ and was determined to be $2227 \mathrm{~W}$. The value of $Q_{s}$ calculated compares well with the values used in the studies of Zhu and Chao (2004) and Selvaraj (2013), which were similar in terms of rotation speed and tool radius. 
In order to implement the heat generation, it is necessary to use the rate of heat input to the workpiece (heat flux $q_{r}$ ); $q_{r}$ was defined by Chao and Qi (1998), which was the first study to simulate heat generation in the FSW process. The heat flux $\left(q_{r}\right)$ is given by:

$q_{r}=\frac{3 Q_{h} r}{2 \pi\left(r_{s}{ }^{3}-r_{p}{ }^{3}\right)}$

where $r_{s}$ is the shoulder radius and $r_{p}$ is the pin radius. It is clear from equation 10 that $q_{r}$ increases with increasing tool radius; this means that during the welding process the highest temperature is expected to be towards the outer edge of the tool shoulder. Equation 10 was applied as a boundary condition in the shoulder region by using a UDF.

A convection thermal boundary condition was applied on the extents of the domain. In line with the work of Daftardar (2009), who determined the values of the heat transfer coefficient by fitting the predicted values with the experimental data using a trial and error method, it was assumed that the top and side surfaces have free air convection with a heat transfer coefficient of $15 \mathrm{~W} \mathrm{~m}^{-2} \mathrm{~K}^{-1}$, while the bottom surface was assumed to be in contact with the backing plate with a heat transfer coefficient of $300 \mathrm{~W} \mathrm{~m}^{-2} \mathrm{~K}^{-1}$ (note that the backing plate itself was not modelled in this study).

In order to assess convergence of the steady-state solution, the values of velocity and temperature at two points (upstream near the tool and in the free stream) were monitored throughout the solution until the change in the velocity and temperature were less than 0.05 $\%$ per iteration. 


\section{Tool wear methodology}

\subsection{Wear model}

A model that has been commonly used in the literature to predict wear in many machine parts and sliding wear damage is Archard's Equation (Gohar and Rahnejat, 2008):

$V=k W S$

where $V$ is the total wear volume; $k$ is the dimensional Archard wear coefficient, which is dependent on the material and surface cleanliness; $W$ is the applied load and $S$ is the sliding distance. In many applications it is necessary to determine the local wear depth at any given position, therefore, equation 11 is modified and known as the modified Archard's Equation as shown in equation 12 (McColl et al., 2004):

$h=k P t V_{\text {slip }}$

where $h$ is the wear depth, $P$ is the contact pressure, $t$ is the time, and $V_{\text {slip }}$ is the relative interface velocity.

Accordingly, tool wear in the FSW process was calculated using the modified Archard equation for a given point on the tool surface; equation 12 is thus reformulated in order to calculate wear depth increment for a given point (McColl et al., 2004):

$\Delta h=k P \Delta t V_{\text {slip }}$

where $\Delta h$ and $\Delta t$ are the wear depth increment and time increment respectively.

Using equation 13, it is possible to calculate the wear depth increment for a given time increment at any point on the FSW tool surface, based on the pressure and slip velocity 
extracted from the CFD model. However, initially the value of wear coefficient was not known; therefore, to derive a value for the wear coefficient, the procedure presented in Figure 3 was used. The values of pressure and slip velocity were extracted from the CFD model, run with the initial tool geometry for the first increment, and then using the experimental tool profile data, an average wear coefficient of $2.36 \times 10^{-13} \mathrm{~mm}^{3} \mathrm{~N}^{-1} \mathrm{~m}^{-1}$ was calculated using equation 13 and the Least Mean Squared Error (LMSE) optimisation method. This value was then used to perform the wear calculations for subsequent increments.

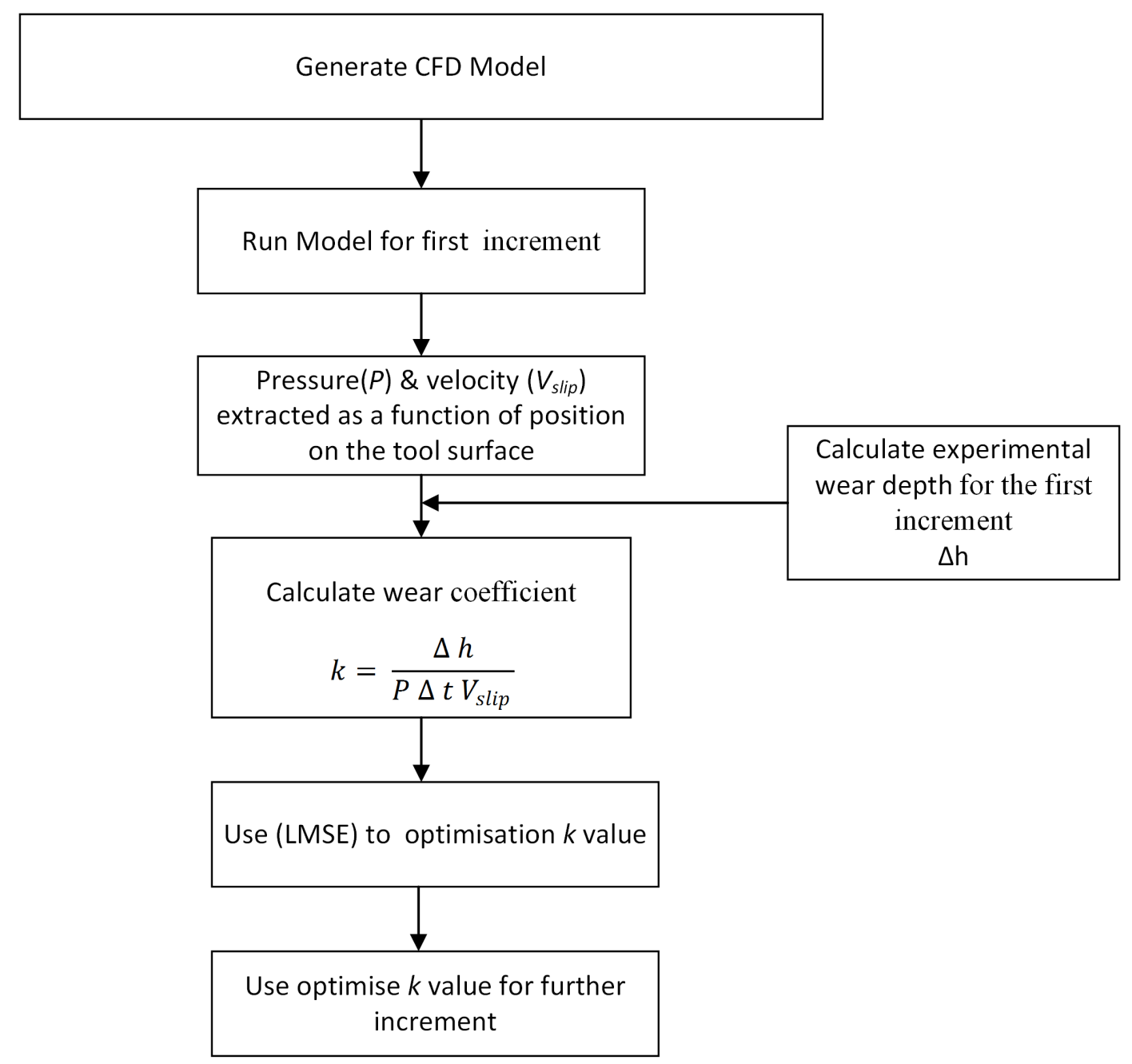

Figure 3 Wear coefficient determination 


\subsection{Wear modelling procedure}

This section describes the methodology that was used to calculate tool wear in the FSW process. The developed approach, which is based on the CFD model detailed previously, is presented schematically in Figure 4.

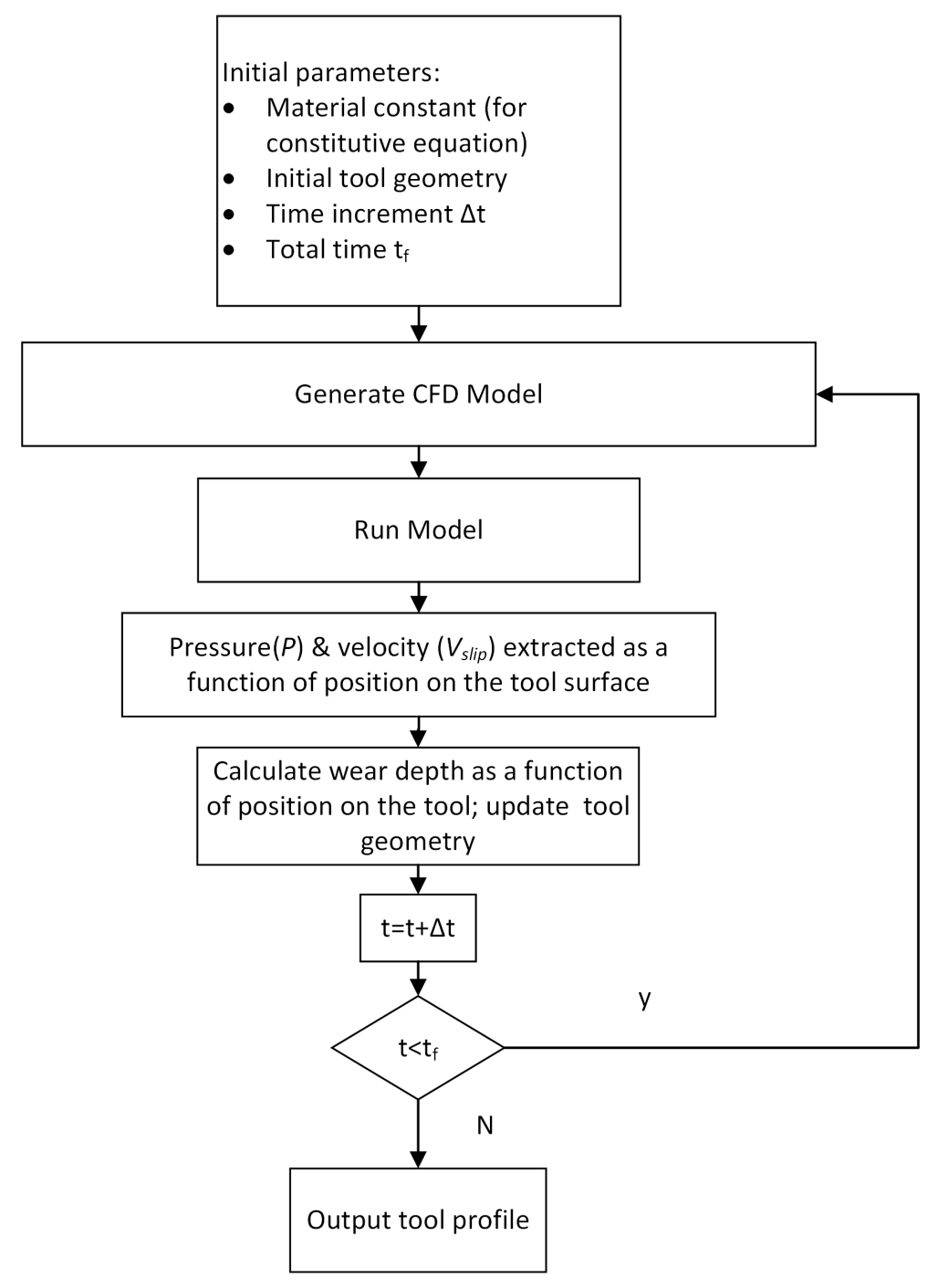

Figure 4 Flow diagram of FSW tool wear simulation.

As can be seen in Figure 4, the first step was the determination of the initial parameters required for the calculation of tool wear; these parameters were material constants for the 
CFD model, initial tool geometry, and the time increment. Once the CFD model of the initial geometry (unworn tool) had been generated, the pressure values and the velocity on the tool surface were extracted. After the CFD model had been solved for the parameters stated in Table 1, and the convergence criteria were met, a data file was exported giving the position, pressure and velocity of 1295 points from four polylines on the tool surface, as shown in Figure 5. A MATLAB script was used to average these data for those polylines to obtain a set of values as a function of tool radial position, representing one tool rotation. In this study only positive values of pressure were considered to contribute to the tool wear and therefore any negative value of pressure was made equal to zero before the averaging calculations. The averaged values were then used to calculate the wear depth for each radial position on the tool surface.

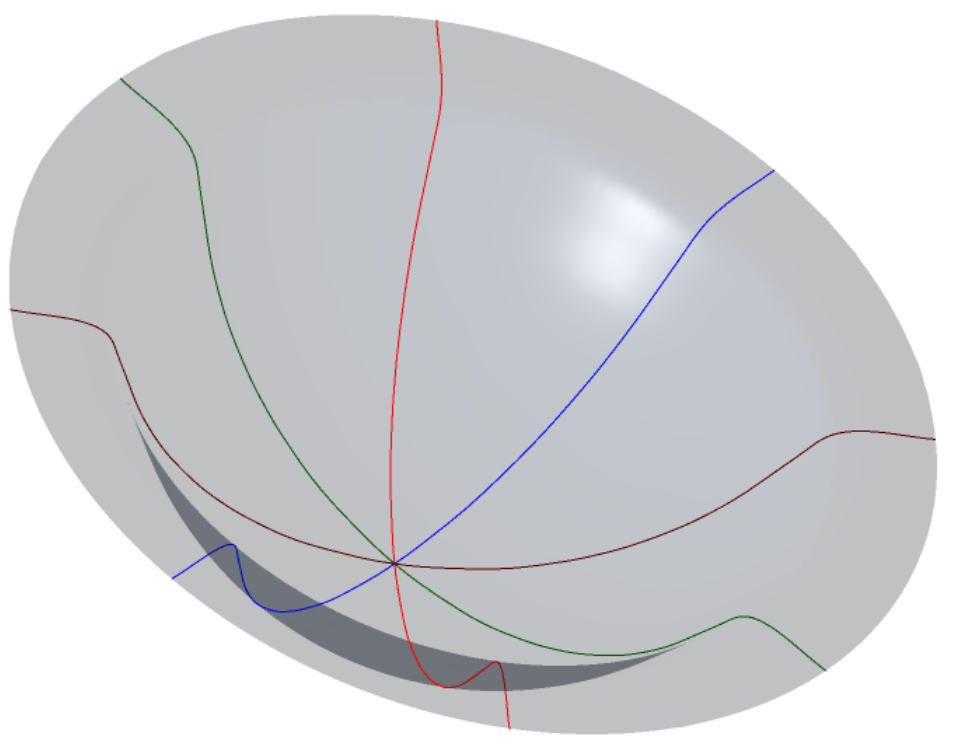

Figure 5 Polylines on the tool surface used to obtain the position, pressure and velocity values.

After the tool wear was calculated for a given time increment, the new tool geometry was defined and the mesh was updated in order to run the CFD model for the next time increment 
to derive the values of pressure and velocity at the tool surface with the revised tool geometry. This process was repeated until $t=t_{f}$.

It should be noted that in the FSW process, the pressure distribution and the slip velocity are not constant over the tool surface, which leads to different wear rates at different locations on the tool surface. Moreover, in order to validate this work, the top surface of the plate was retained as a reference position for measuring the wear depth. Since the wear at the shoulder is higher than the tip, as the tool position is adjusted to keep the shoulder on the top surface of the plate, the tip intrudes deeper into the plate.

\section{$5 \quad$ Results}

\subsection{Computed temperature fields}

In this study, three $\mathrm{x}-\mathrm{z}$ planes were used to plot the predicted temperature contours from the model at three positions through the thickness of the plate; the first plane was on the top surface of the plate, the second plane was at the pin tip, and the third plane was on the bottom surface of the plate. The simulated temperature contours are shown in Figure 6. It is evident that the peak temperature is on the top surface at the shoulder edge, and has a value of 1498 K. 


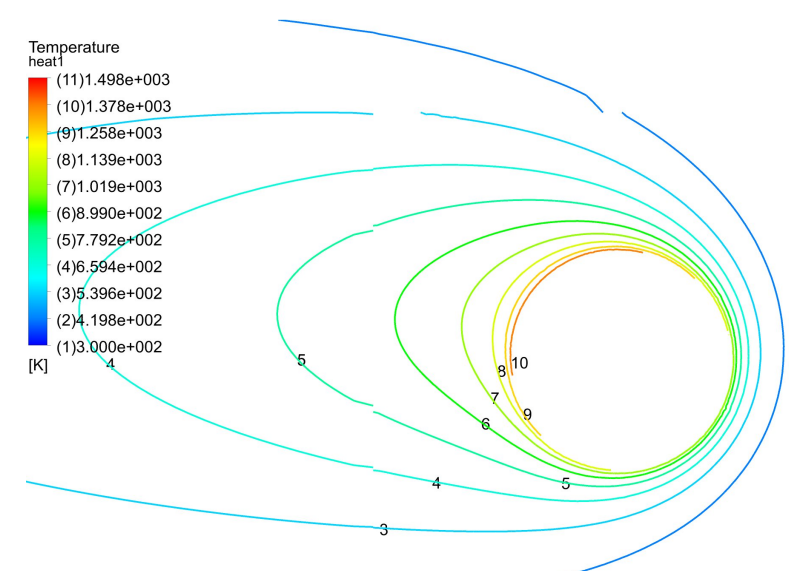

(a)

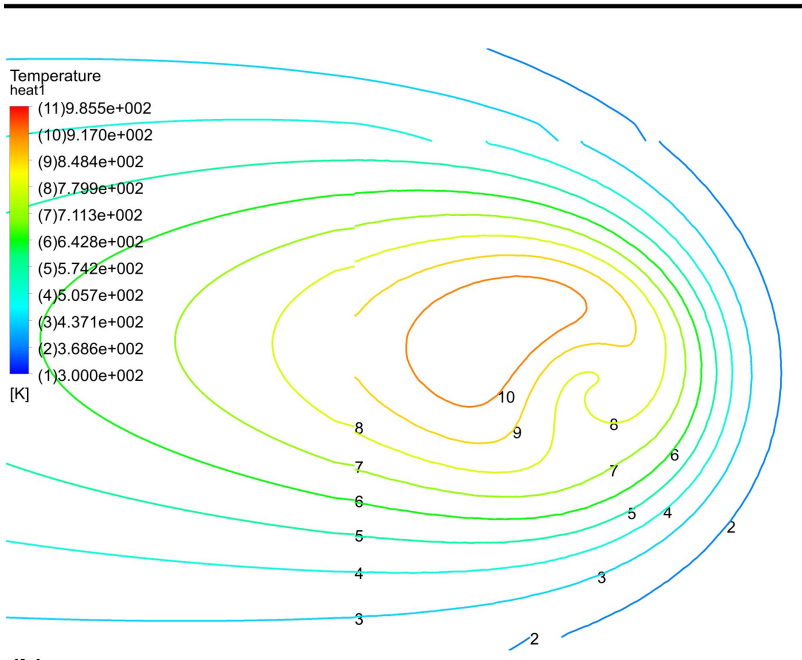

(b)

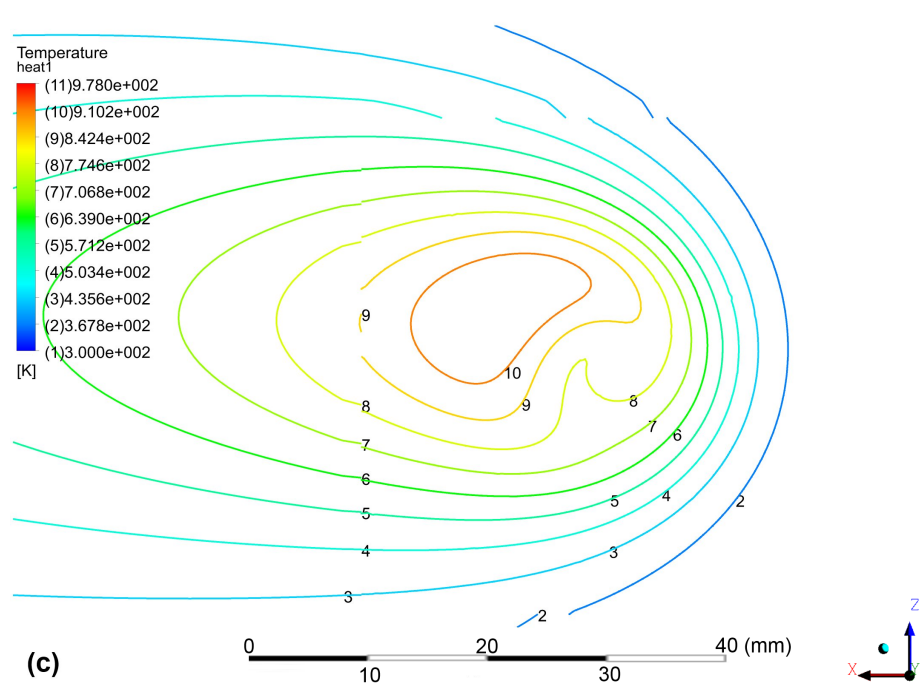

Figure 6 Plot of the temperature distribution at $2 \times 10^{3} \mathrm{~mm}$ weld distance: (a) on the top surface of the plate, (b) on a plane at the pin tip and (c) on the bottom surface of the plate for the initial geometry.

As we go further down the pin (Figure 6b), the predicted the temperature reduces by $30 \%$ to $986 \mathrm{~K}$. On the bottom surface of the plate (Figure 6c), the peak temperature during the 
welding process is $978 \mathrm{~K}$. The most important thing which can be observed from these predicted temperature contours is that the melting temperature , $T_{m}$, of the 304 stainless steel, which is $1698 \mathrm{~K}$, is not reached; this is consistent with the study by Zhu and Chao (2004). It is also important to note that the temperature distribution is a function of the rotation speed and tool radius, as presented in equation 10. Therefore, it should be expected that the temperature is highest at the top surface of the plate where the primary heat source (the shoulder) is situated and that the temperature decreases through the thickness. The simulated temperature on the top surface of the plate shows a good agreement with the simulated value by Selvaraj (2013), although there are slight differences in process parameters and tool geometry between that work and the current study, as shown in Table 4.

Table 4 Comparison between predicted peak temperature in the shoulder area with the work of Selvaraj (2013)

\begin{tabular}{|c|c|c|c|}
\cline { 2 - 4 } \multicolumn{1}{c|}{} & $\begin{array}{c}\text { Rotation speed / } \\
\text { rpm }\end{array}$ & $\begin{array}{c}\text { Shoulder } \\
\text { radius / mm }\end{array}$ & $\begin{array}{c}\text { Peak temperature at the } \\
\text { shoulder } / \mathbf{K}\end{array}$ \\
\hline Selvaraj (2013) & 300 & 19 & 1430 \\
\hline Current work & 225 & 18 & 1498 \\
\hline
\end{tabular}

\subsection{Material flow behaviour (velocity distribution and pressure)}

To analyse the flow behaviour in the FSW process around the tool, and to develop understanding of the flow patterns for this particular tool design, velocity streamlines were used to examine how the material flows around the tool and to identify the region of plastic deformation near the tool. Streamlines were plotted on two planes: the first plane was a horizontal x-z plane at the top surface of the plate, while the second was an $x-y$ plane parallel to the weld direction on the axis of the pin rotation. The area around the tool was divided in 
to several zones as shown in Figure $7 \mathrm{~b}$ in order to investigate the flow patterns in this tool design.
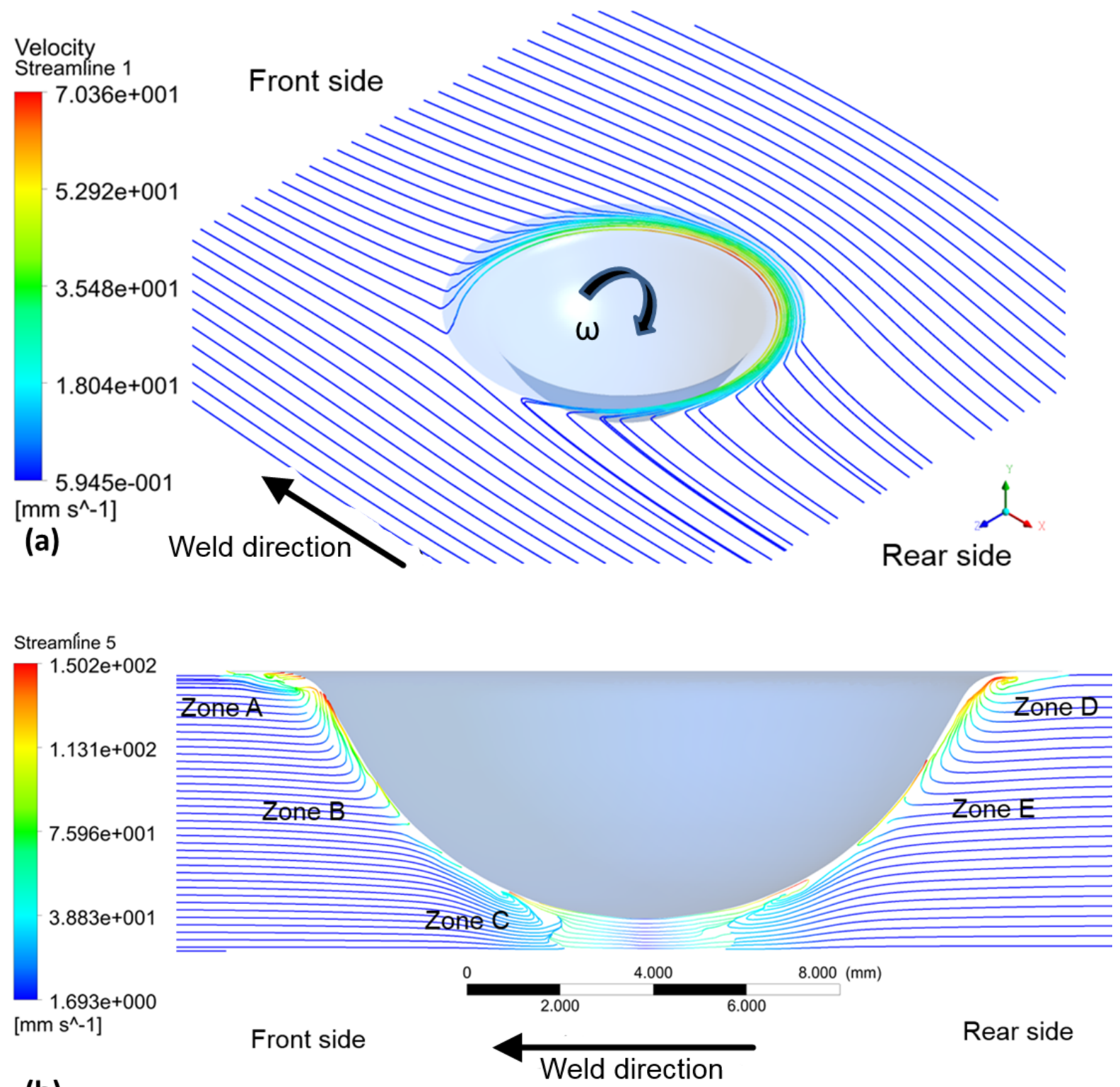

(b)

Figure 7 Stream-lines in different planes; (a) a horizontal x-z plane at the top surface of the plate, (b) x-y plane parallel to weld direction.

Figure 7a shows that the flow of the material near the tool is dominated by the tool rotation; flow of this type is quite commonly reported for the FSW process (Colegrove et al., 2007, Hasan et al., 2015, Su et al., 2015). It can be seen from the velocity streamlines in Figure 7b 
that zones $\mathrm{A}$ and $\mathrm{D}$ have high deformation due to the presence of high velocity gradients. On the front side of the tool in zones A and C, some material in the shear deformation zone is moved upward, while some parts of the material are pulled down through the thickness of the plate. It is worth mentioning that the results of this behaviour of the flow show a good agreement with the findings of (Colegrove and Shercliff, 2004) and (Grujicic et al., 2012). On the rear side of the tool, in zones D and E, the material is pulled down by the tool rotation, causing separation of the material from the tool surface. The plot of streamlines explains the interaction of the axial flow with the pin; causing a bifurcation of the flow past the pin, which leads to an increase in the pressure at that position, as shown in Figure 8 where the contours of the pressure distribution on the tool surface are plotted in the $\mathrm{x}-\mathrm{y}$ plane.

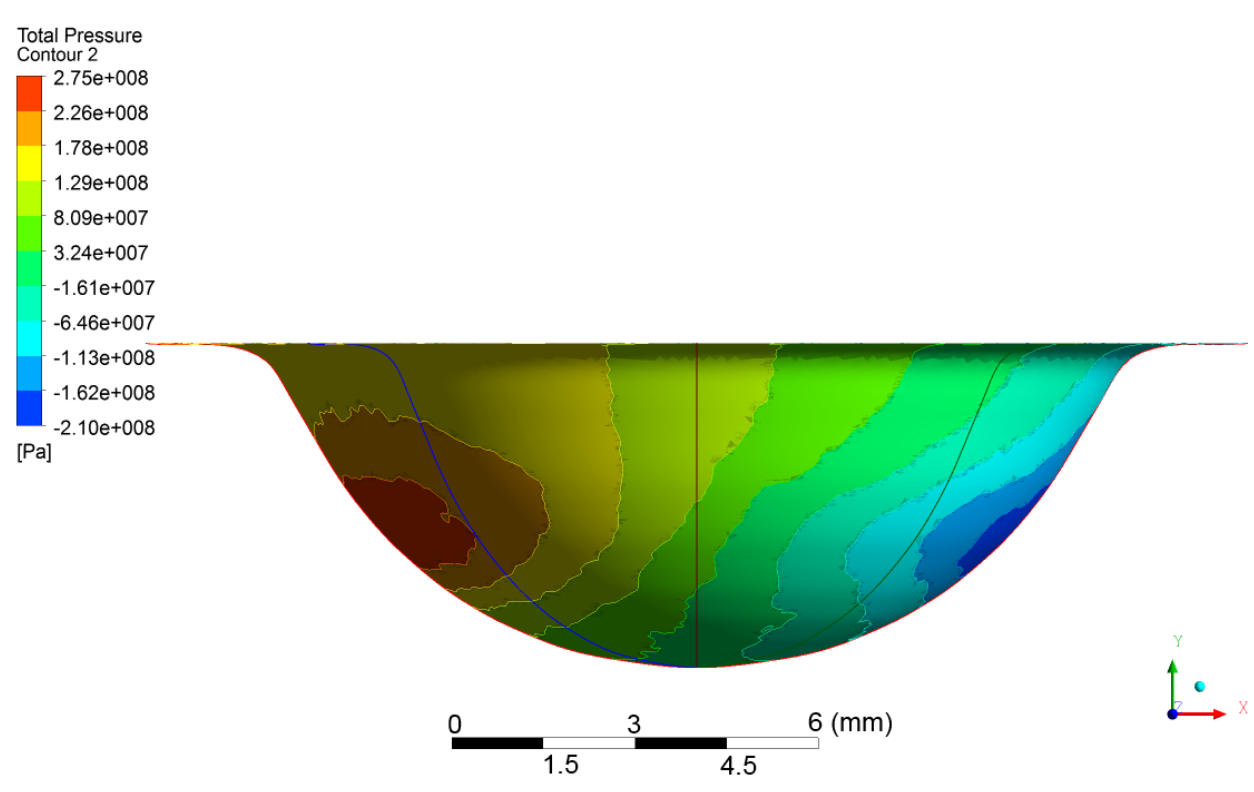

Figure 8 View in the x-direction of pressure contours on the tool surface for the initial geometry.

In Figure 9, the streamline plots are detailed from two initial points to further analyse the flow behaviour. The first point, S1, was located in the pin mid-zone, at a vertical position of 3 $\mathrm{mm},-\mathrm{x}=15 \mathrm{~mm}$ and $\mathrm{z}=0 \mathrm{~mm}$, while, $\mathrm{S} 2$ was located in the tool tip region at a vertical position of $0 \mathrm{~mm}, \mathrm{x}=-15 \mathrm{~mm}$ and $\mathrm{z}=0 \mathrm{~mm}$, where $(0,0,0)$ is the pin tip. Once near the pin, the material from S1 is wrapped around the tool and undergoes more than one rotation around 
the tool surface before separation occurs; this finding is consistent with Owen (2006). However, from S2 the material flows around the tool without completing a full rotation and then separates. It is possible to determine from Figure 9 that near the tool tip region, separation occurs leading to a decreases in pressure in that region as shown in Figure 8.

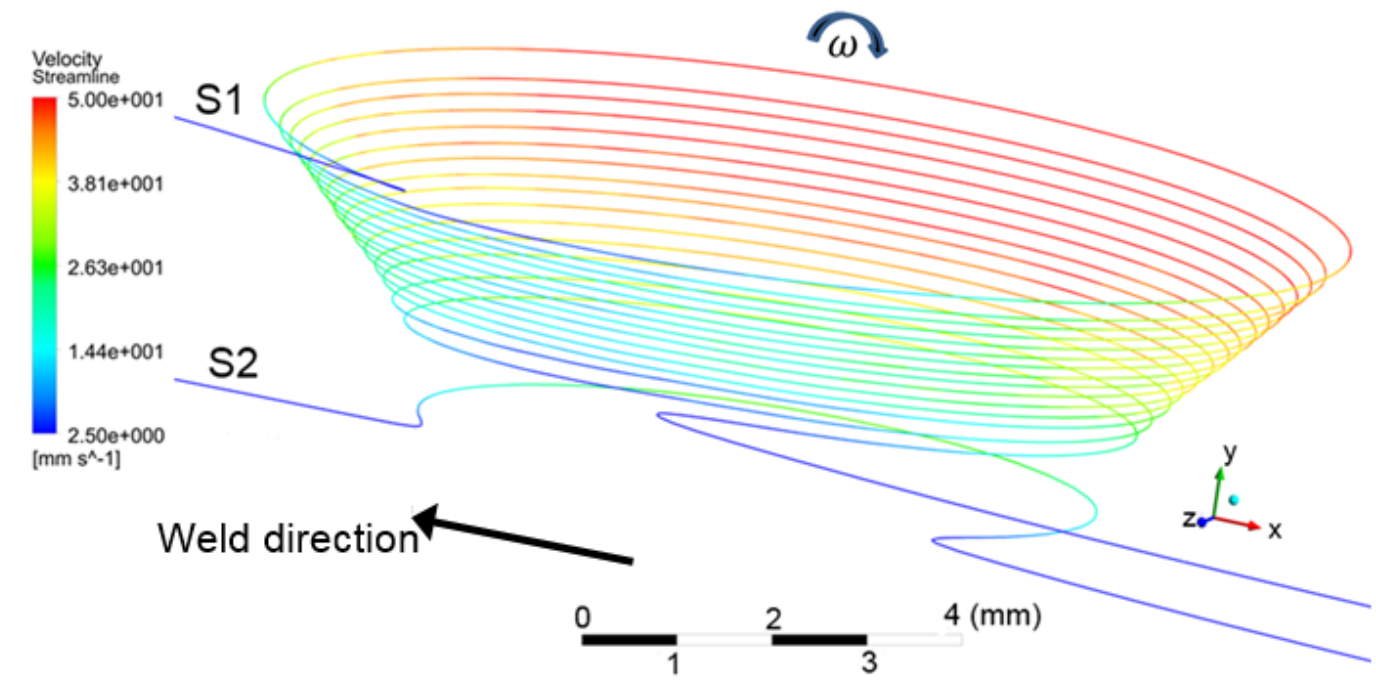

Figure 9 Stream-line plots showing flow separation from the tool surface at $225 \mathrm{rpm}$ and $2.5 \mathrm{~mm} \mathrm{~s}^{-1}$ weld speed. S1: stream line at mid pin zone; vertical position $3 \mathrm{~mm}, \mathrm{~S} 2$ : stream line at tool tip zone; vertical position $0 \mathrm{~mm}$.

\subsection{Tool wear prediction}

To achieve sufficient confidence in the wear methodology for predicting the tool wear in FSW, the approach must be thoroughly validated. The tool profile was measured using a shadowgraph at increments of distance and the incremental wear depth was calculated. Moreover, wear depth for the simulation tool profile cases was predicted using the average data of pressure and velocity. The average pressure distribution on the tool surface predicted at different radial positions with the initial tool geometry, as detailed in Figure 1, is presented in Figure 10. The overall trend shows a low pressure region near the pin tip ( $\mathrm{r}=0$ to $1 \mathrm{~mm})$, and that the pressure increases until it reaches a peak value at $r=5.2 \mathrm{~mm}$ (tool mid surface). Following the maximum, the pressure decreases and there is no significant change until the shoulder region ( $\mathrm{r}=7$ to $8.9 \mathrm{~mm})$. 


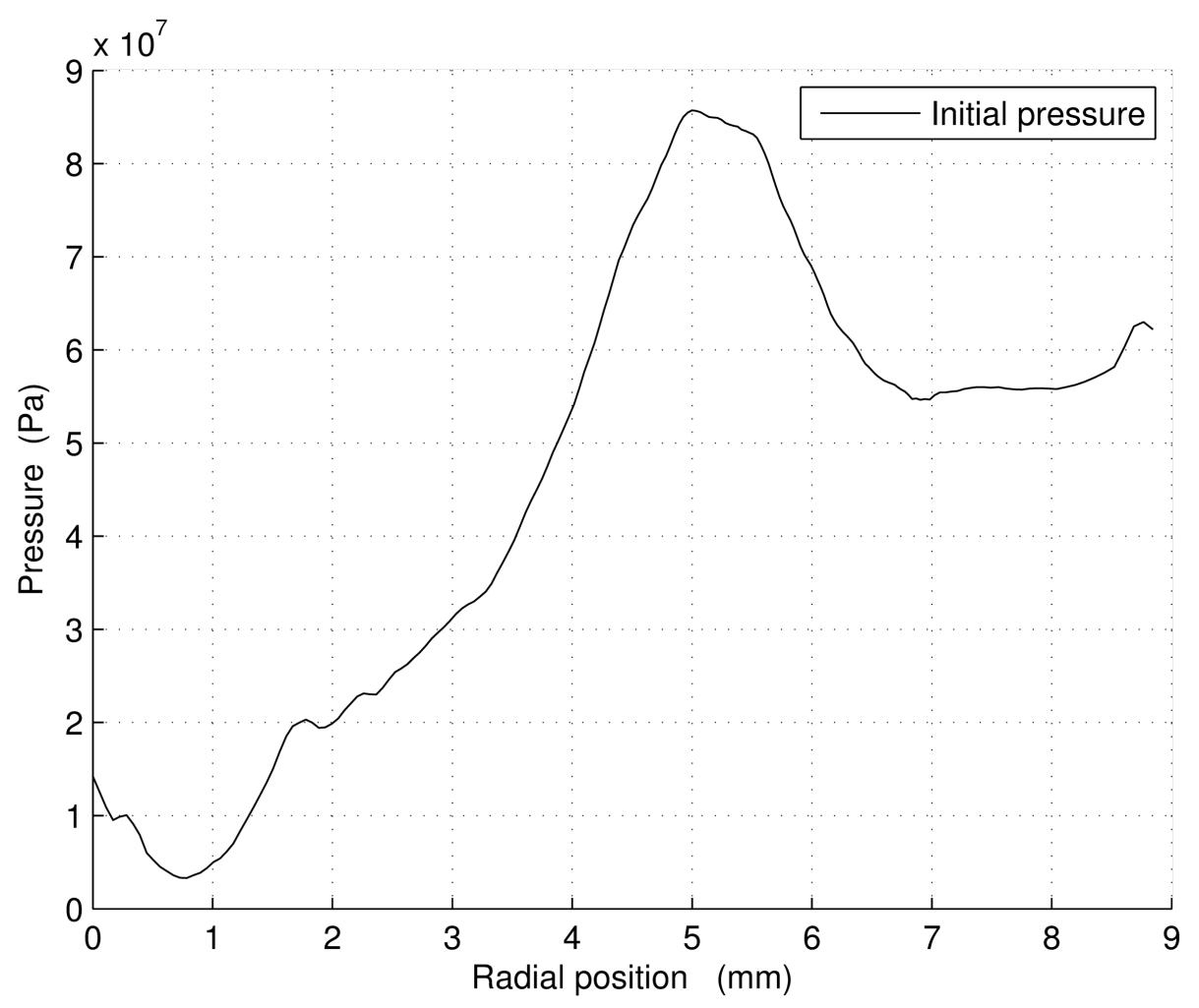

Figure 10 Average pressure distributions as a function of position on the tool surface for the initial geometry used for wear calculation.

\subsubsection{Wear depth results}

Figure 11a shows the measured values of the wear depth increment for the experimental and predicted tool profile for the increment of weld distance from 0 to $2 \times 10^{3} \mathrm{~mm}$. The data show that no significant wear occurs near the pin tip. Overall trends of the experimental and simulation data show that wear depth increment increases steadily from the pin tip to the mid pin region, which is shown in Figure $1 \mathrm{~b}$; at close to $\mathrm{r}=5 \mathrm{~mm}$, the trend is for the wear depth increment to fall steadily before finally increasing at $r=7.5 \mathrm{~mm}$. As can be seen in Figure 11a, the simulated results show a good agreement with experimental data from the pin tip to $r$ $\approx 6.5 \mathrm{~mm}$. After this distance, some mismatch can be observed until the shoulder edge (at $\mathrm{r}=$ $8.9 \mathrm{~mm})$. This can be attributed to the use of single-phase flow and finite volume method 
(FVM) requiring a non-deforming wall to be specified as the top surface of the plate, which leads to an increase in the pressure in that area. 

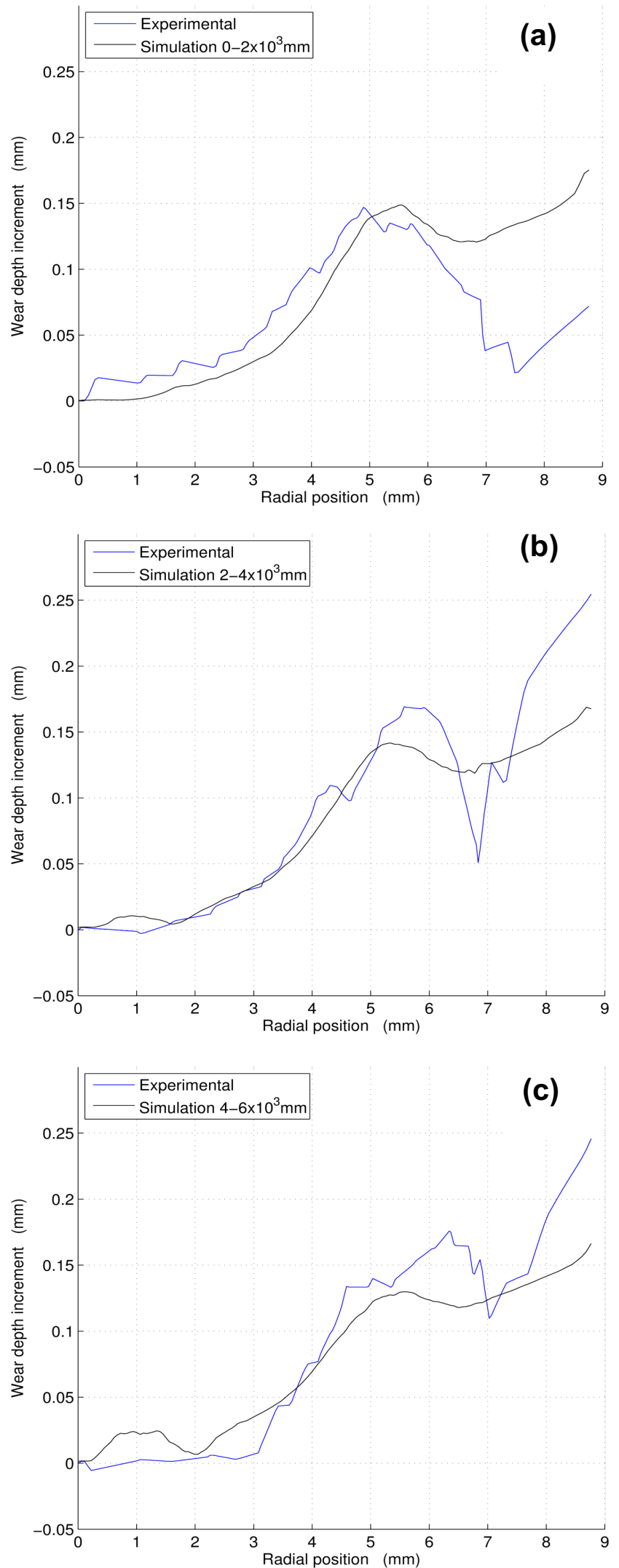

Figure 11 Plot of the wear depth along the tool surface after an increment of weld distances of; (a) $0-2 \times 10^{3} \mathrm{~mm}$, (b) of $2-4 \times 10^{3} \mathrm{~mm},(\mathrm{c})$ of $2-4 \times 10^{3} \mathrm{~mm}$. 
The results of the tool wear for the increment of weld distance from $2-4 \times 10^{3} \mathrm{~mm}$ (Figure 11b) show a similar behaviour to those in Figure 11a. At $\mathrm{r}=5 \mathrm{~mm}$, the value of the wear depth increment was $0.13 \mathrm{~mm}$, which is slightly lower than that calculated for the increment in weld distance from $0-2 \times 10^{3} \mathrm{~mm}$. The numerically computed results are in good agreement with the general trend of the experimental results; however, some over prediction can be seen near the edge of the shoulder region, as in Figure 11a.

A similar trend is seen in Figure 11c as in Figure 11a in terms of wear depth on the tool surface; the results show that slightly higher wear occurred near the pin tip, which could be because of localized pressure in this region. The reason for this is the short distance between the bottom plate surface and the pin tip, as explained in section 3.2 (wall boundary condition). Again, good agreement was obtained when comparing the results of the simulated and experimental wear depth increment and again, in common with the results presented in Figure 11a and Figure 11b, a mismatch can be seen near the edge off the shoulder region.

The simulated results for the three increments of weld distance show that the highest material loss occurs in the shoulder area and at the mid-pin region $(\mathrm{r} \approx 5 \mathrm{~mm})$. There is a greater likelihood of obtaining a high value for wear depth at the shoulder because high plastic deformation occurs within the shoulder region and wear is caused by high pressure and high velocity differences. In addition, as shown in Figure 7, on the front side, the flow is obstructed by the tool in the mid-pin region (stagnation point) and then the material flows upwards or flows down, so there is already a high pressure in this region. For all the weld distances, the peak increment of wear was between $0.13-0.15 \mathrm{~mm}$ at a radius of $5 \mathrm{~mm}$ ). Finally, it is important to conclude that the predicted tool wear results showed a good agreement with the measured values, with a maximum error of less than $19 \%$ and average error for the three cases of less than $13 \%$, when compared with the experimental results in the zone located below the shoulder edge and pin root. 


\subsubsection{Tool profile results}

Figure 12 shows the evolution of the tool geometry at different weld distances; it is evident that very little wear was predicted during welding near the pin tip; however, in other regions on the tool surface, it can be seen that the wear increased as the weld distance increased. The tool length increased (due to wear on the shoulder increasing the effective length of the tool) by only $0.5 \mathrm{~mm}$ after a weld distance of $6 \times 10^{3} \mathrm{~mm}$. It can be argued that this is due to a combination of the rapidly changing flow at dome-shoulder junction and the increased peripheral speed of the tool out towards the edge of the shoulder. On the other hand, no significant change in the tool shape can be observed, even after a weld distance of $6 \times 10^{3} \mathrm{~mm}$, which means this tool is able to retain its original dome shape and it would therefore be assumed that the tool was able to continue producing welds under these circumstances.

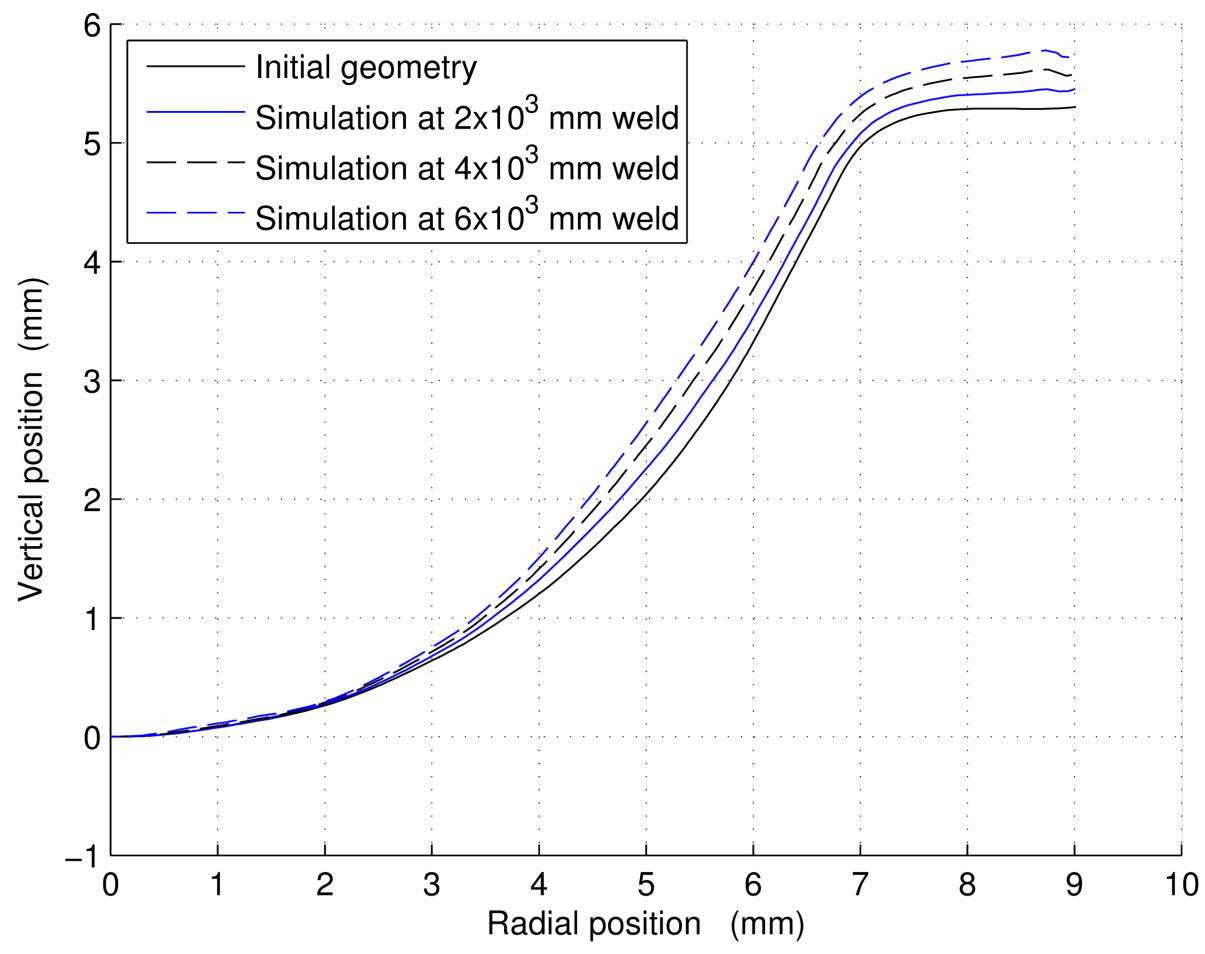

Figure 12 Tool profile after different welding distances. 


\section{Discussion}

It should be noted that the pressure distribution generated due to material flow during the process causes wear on the tool as concluded by the study of Prado et al. (2003) and Ke et al. (2004).

The results of the model show that the flow of material near the tool is dominated by the tool rotation. It also demonstrates the circular behaviour of the flow within the tool region. The streamline plots reveal that the material on the front side of the tool near the shoulder is pushed up; on the rear side of the tool it flows down; and at the lower part of the tool the material flows downward on both sides of the tool. These streamline plots can give a good explanation for the flow patterns for this particular tool design. The numerically computed flow patterns are in good agreement with the general findings that have been reported in the literature (Seidel and Reynolds, 2001, Nandan et al., 2007) in terms of the stagnation and separation points, and for the vertical flow motion near the tool surface.

The results of the developed methodology in terms of tool wear show that, for all three increments in weld distance, in the region between $\mathrm{r} \approx 0$ to $5.5 \mathrm{~mm}$, the wear depth increment increased gradually reaching a peak at $\approx 5.5 \mathrm{~mm}$; thereafter, the increment of wear depth fell until $\mathrm{r} \approx 7 \mathrm{~mm}$ and then started to increase towards the shoulder edge. A good correlation was obtained with experimental data in terms of wear depth. Clearly, the proposed approach is able to predict tool wear in the FSW process based on the investigation into the effect of the highly viscous flow on the FSW tool.

In all three cases, the tool was worn radially and vertically. To summarise the main findings, this tool design, even when worn, largely retains the original dome design as shown in Figure 12. The mechanism of the wear for this particular tool in these circumstances is deformation 
and sliding wear, and this finding is confirmed by previous studies (Michael, 2012, Thompson, 2010, Siddiquee and Pandey, 2014).

Furthermore, the inconsistency of the results in some regions can be attributed to the use of a one-phase flow model. Clearly, one of the most important problems with using the FVM (Finite Volume Method) is in defining the boundary where the material being welded begins to deform. This boundary is defined as the top surface of the workpiece in this case, by assuming it to be a non-deforming wall (Colegrove et al., 2007); this assumption prevents material flow past the boundary and leads to an increase in the pressure close to that position. Another important factor which causes this pressure distribution in Figure 10 may be bulge formation, which has been observed in the literature (Fairchild et al., 2011). Indeed, all these factors cause some difficulties, which leads to the inconsistencies in the results produced using this method near the shoulder area.

\section{Conclusions}

In this study, a methodology for calculating tool wear in FSW based on a CFD model has been developed to predict the effect of the deformation of the highly viscous flow around the tool on tool wear. A modified Archard equation, implemented in MATLAB, was used to calculate the wear on the dome shaped FSW tool. A validation process has been carried out in this study in order to obtain robust results when using this methodology.

The key findings of the work can be summarised as follows:

- The results of the FLUENT CFD model showed a good agreement with the literature data for peak temperature.

- The velocity streamlines indicate that a rapidly changing flow occurs at the shoulder edge, potentially leading to high tool wear in this region. 
- The velocity streamlines show the interaction of the axial flow with the pin; causing a bifurcation of the flow past the pin at the mid-point, which leads to an increase in the pressure values at that position.

- The proposed approach is able to predict tool wear associated with highly viscous flow around the FSW tool.

- The results of the predicted tool wear showed a good agreement with a maximum error of less than $19 \%$ and average error for the three cases of less than $13 \%$, when compared with the experimental results at zone located below shoulder edge and pin root.

- The inconsistency in the results near the shoulder can be developed further through the use of a two phase approach and also by considering the loading history at each location on the tool surface with the potential to yield geometry independent, variable wear coefficient values.

- From the results it can be concluded that the wear mechanism for this particular tool in these circumstances is sliding wear.

- This modelling approach could be used to improve understanding of the effective limits of tool use for welding, and as a method for calculating tool wear (as a function of tool geometry and basic FSW process parameters) without the need for experimental trials.

\section{Acknowledgements}

The authors would like to acknowledge the support of the Higher Committee for Education Development in Iraq (HCED) for the research scholarship. They are also grateful for access to the University of Nottingham High Performance Computing (HPC) Facility. 


\section{References}

AKKÖK, M., ACAR, B. \& AÇMAZ, E. 2013. Experimental analysis and wear modeling for mechanical components of a typical rail launcher. Wear, 306, 1-9.

BELYAKOV, A., MIURA, H. \& SAKAI, T. 1998. Dynamic recrystallization under warm deformation of a 304 type austenitic stainless steel. Materials Science and Engineering: A, 255, 139-147.

BUFFA, G., FRATINI, L., MICARI, F. \& SETTINERI, L. 2012. On the Choice of Tool Material in Friction Stir Welding of Titanium Alloys. Proceedings of NAMRI/SME, 40.

CHAO, Y. J. \& QI, X. 1998. Thermal and thermo-mechanical modeling of friction stir welding of aluminum alloy 6061-T6. Journal of materials processing and manufacturing science, 7, 215-233.

CHAO, Y. J., QI, X. \& TANG, W. 2003. Heat transfer in friction stir welding-experimental and numerical studies. Journal of manufacturing science and engineering, 125, 138-145.

CHEN, Z., PASANG, T. \& QI, Y. 2008. Shear flow and formation of Nugget zone during friction stir welding of aluminium alloy 5083-0. Materials Science and Engineering: A, 474, 312-316.

COLEGROVE, P. \& SHERCLIFF, H. 2004. Development of Trivex friction stir welding tool Part 2-three-dimensional flow modelling. Science and Technology of Welding \& Joining, 9, 352-361.

COLEGROVE, P. A. 2004. Modelling of friction stir welding. University of Cambridge.

COLEGROVE, P. A., SHERCLIFF, H. R. \& ZETTLER, R. 2007. A Model for Predicting the Heat Generation and Temperature in Friction Stir Welding from the Material Properties. Science and Technology of Welding \& Joining, Volume 12, Number 4, May 2007, pp. 284-297, 12, 284-297.

DAFTARDAR, S. 2009. Laser Assisted Friction Stir Welding: Finite Volume Method and Metaheuristic Optimization. Louisiana State University

ERSOY-NÜRNBERG, K., NÜRNBERG, G., GOLLE, M. \& HOFFMANN, H. 2008. Simulation of wear on sheet metal forming tools-An energy approach. Wear, 265, 1801-1807.

FAIRCHILD, D. P., FORD, S. J., KUMAR, A., NISSLEY, N. E., BIERY, N. E. \& MACIA, M. L. 2011. Butt weld and method of making using fusion and friction stir welding. Google Patents.

GAN, W., LI, Z. \& KHURANA, S. 2007. Tool materials selection for friction stir welding of L80 steel. Science and Technology of Welding and Joining, 12, 610-613.

GIBSON, B., LAMMLEIN, D., PRATER, T., LONGHURST, W., COX, C., BALLUN, M., DHARMARAJ, K., COOK, G. \& STRAUSS, A. 2014. Friction stir welding: process, automation, and control. Journal of Manufacturing Processes, 16, 56-73.

GOHAR, R. \& RAHNEJAT, H. 2008. Fundamentals of tribology, World Scientific.

GRUJICIC, M., ARAKERE, G., PANDURANGAN, B., OCHTERBECK, J., YEN, C., CHEESEMAN, B., REYNOLDS, A. \& SUTTON, M. 2012. Computational Analysis of Material Flow During Friction Stir Welding of AA5059 Aluminum Alloys. Journal of Materials Engineering and Performance, 21, 1824-1840.

HAMILTON, C., DYMEK, S. \& SOMMERS, A. 2008. A thermal model of friction stir welding in aluminum alloys. International Journal of Machine Tools and Manufacture, 48, 1120-1130. 
HASAN, A., BENNETT, C. \& SHIPWAY, P. 2015. A numerical comparison of the flow behaviour in Friction Stir Welding (FSW) using unworn and worn tool geometries. Materials \& Design, 87, 1037-1046.

ISHIKAWA, T., FUJII, H., GENCHI, K., IWAKI, S., MATSUOKA, S. \& NOGI, K. 2009. High speed-high quality friction stir welding of austenitic stainless steel. ISIJ international, 49, 897-901.

KE, L., XING, L. \& INDACOCHEA, J. 2004. Material flow patterns and cavity model in friction-stir welding of aluminum alloys. Metallurgical and Materials Transactions $B, 35,153-160$.

LIECHTY, B. C. 2008. Material Flow Behavior in Friction Stir Welding.

MANDAL, S., RICE, J. \& ELMUSTAFA, A. 2008. Experimental and numerical investigation of the plunge stage in friction stir welding. Journal of materials processing technology, 203, 411-419.

MCCOLL, I., DING, J. \& LEEN, S. 2004. Finite element simulation and experimental validation of fretting wear. Wear, 256, 1114-1127.

MCPHERSON, N., GALLOWAY, A., CATER, S. \& OSMAN, M. A comparison between single sided and double sided friction stir welded 8mm thick DH36 steel plate. Trends in Welding Research 2012: Proceedings of the 9th International Conference, 2013. ASM International, 284.

MICHAEL, E. 2012. The Effects of Tool Texture on Tool Wear in Friction Stir Welding of X70 Steel. Ohio State University.

MURR, L. 2010. A review of FSW research on dissimilar metal and alloy systems. Journal of Materials Engineering and Performance, 19, 1071-1089.

NANDAN, R., ROY, G., LIENERT, T. \& DEBROY, T. 2006. Numerical modelling of 3D plastic flow and heat transfer during friction stir welding of stainless steel. Science and Technology of Welding \& Joining, 11, 526-537.

NANDAN, R., ROY, G., LIENERT, T. \& DEBROY, T. 2007. Three-Dimensional heat and material flow during friction stir welding of mild steel. Acta Materialia, 55, 883895.

NKHOMA, C. \& KASANALOWE, R. 2014. Hot Working Characteristics of AISI 321 in Comparison to AISI 304 Austenitic Stainless Steels.

OWEN, C. B. 2006. Two dimensional friction stir welding model with experimental validation. Master of Science, Brigham Young University.

POELMAN, L. 2011. Characterization of tools for friction stir welding of steels. Master in Engineering, Ghent University

PRADO, R., MURR, L., SOTO, K. \& MCCLURE, J. 2003. Self-optimization in tool wear for friction-stir welding of $\mathrm{Al} 6061+20 \% \mathrm{Al}_{2} \mathrm{O}_{3}$ MMC. Materials Science and Engineering: A, 349, 156-165.

PRATER, T. \& STRAUSS, A. 2010. Statistical modelling and prediction of wear in Friction Stir welding of a metal matrix composite (AL 359/SIC/20P). Journal of Manufacturing Technology Research, 2, 1-13.

SCHMIDT, H., HATTEL, J. \& WERT, J. 2004. An analytical model for the heat generation in friction stir welding. Modelling and Simulation in Materials Science and Engineering, 12, 143.

SEIDEL, T. \& REYNOLDS, A. 2001. Visualization of the material flow in AA2195 frictionstir welds using a marker insert technique. Metallurgical and Materials Transactions A, 32, 2879-2884.

SELVARAJ, M. 2013. A temperature dependent slip factor based thermal model for friction stir welding of stainless steel. Sadhana, 38, 1393-1405. 
SHINDO, D., RIVERA, A. \& MURR, L. 2002. Shape optimization for tool wear in the friction-stir welding of cast AI359-20\% SiC MMC. Journal of Materials Science, 37, 4999-5005.

SIDDIQUEE, A. N. \& PANDEY, S. 2014. Experimental investigation on deformation and wear of WC tool during friction stir welding (FSW) of stainless steel. The International Journal of Advanced Manufacturing Technology, 73, 479-486.

SINHA, P., MUTHUKUMARAN, S. \& MUKHERJEE, S. 2008. Analysis of first mode of metal transfer in friction stir welded plates by image processing technique. Journal of Materials Processing Technology, 197, 17-21.

SU, H., WU, C. S., BACHMANN, M. \& RETHMEIER, M. 2015. Numerical modeling for the effect of pin profiles on thermal and material flow characteristics in friction stir welding. Materials \& Design, 77, 114-125.

SUED, M., PONS, D., LAVROFF, J. \& WONG, E. 2014. Design features for bobbin friction stir welding tools: Development of a conceptual model linking the underlying physics to the production process. Materials \& Design, 54, 632-643.

TELLO, K. E., GERLICH, A. P. \& MENDEZ, P. F. 2010. Constants for hot deformation constitutive models for recent experimental data. Science and Technology of Welding \& Joining, 15, 260-266.

THOMPSON, B. T. 2010. Tool Degradation Characterization in the Friction Stir Welding of Hard Metals. The Ohio State University.

WANG, J., SU, J., MISHRA, R. S., XU, R. \& BAUMANN, J. A. 2014. Tool wear mechanisms in friction stir welding of Ti-6Al-4V alloy. Wear, 321, 25-32.

ZHU, X. \& CHAO, Y. 2004. Numerical simulation of transient temperature and residual stresses in friction stir welding of 304L stainless steel. Journal of materials processing technology, 146, 263-272. 